\title{
Formação de professores e o Programa Institucional de Bolsa de Iniciação à Docência (PIBID): apontamen- tos sobre avanços e contradições de um programa
}

Teacher training and the Programa Institucional de Bolsa de Iniciação à Docência (PIBID): presentations regarding progress and contradictions of a program

Formación de profesores y el Programa Institucional de Bolsa de Iniciação à Docência (PIBID): observaciones sobre avances y contradicciones de un programa

\author{
Giovana Maria Belém Falcão* \\ Isabel Maria Sabino de Farias*
}

DOI: http://dx.doi.org/10.20435/serie-estudos.v22i44.916

\begin{abstract}
Resumo
Nas últimas décadas, avultam análises destacando a urgência e a importância do estabelecimento de vínculos mais estreitos entre as instituições de formação e a escola. O Programa Institucional de Bolsa de Iniciação à Docência (PIBID) emerge nesse cenário visando estimular e valorizar a opção pelo magistério, iniciativa que, em 2017, registra dez anos de implantação. Quais diretrizes delineiam esse Programa? Que avanços e contradições podem ser identificados na configuração do PIBID desde sua primeira edição? Essas inquietações dão corpo ao exercício de problematização da temática neste escrito. No centro das reflexões, estão as diretrizes norteadoras e delineadoras do Programa, assim como seus avanços e contradições. O exame da temática foi realizado com suporte na análise documental das seguintes fontes: referências legais e editais lançados desde o início do PIBID. O acesso aos documentos aconteceu por consulta direta ao sítio da Coordenação de Aperfeiçoamento de Pessoal de Nível Superior (CAPES). O referencial teórico apoiou-se nas formulações de autores como Nóvoa, Garcia e Farias. A análise qualitativa evidenciou que o PIBID apresenta forte potencial de socialização profissional, embora também se mostre com contradições, delineando-se ora numa perspectiva de ruptura com processos técnicos e pragmáticos, ora afirma e se apoia em tais processos. Instituir políticas de formação docente fortes e abrangentes permanece, assim, um desafio neste início do século XXI.
\end{abstract}

Palavras-chave

Formação docente; PIBID; Educação Básica.

* Universidade Estadual do Ceará (UECE), Fortaleza, Ceará, Brasil. 


\begin{abstract}
Over the last few decades, there have been analyzes highlighting the urgency and the importance of establishing closer links between training institutions and the schools. The Programa Institucional de Bolsa de Iniciação à Docência (PIBID) rises in this scenario aiming to motivate and give value to the option of teachership. An initiative that in 2017 celebrates its 10th implementation anniversary. Which guidelines outline this program? What advances and contradictions can be identified in PIBID's configuration since its first edition? These concerns are present in the problematization exercise of the theme in this paper. Right in the center of such reflections are the guiding and delineating guidelines of the program, as well as its advances and contradictions. Examination of its thematic was carried out being supported by the analysis of documents of the following sources: legal references and edicts launched since the beginning of PIBID. Access to such documents happened via Coordenação de Aperfeiçoamento de Pessoal de Nível Superior (CAPES) website. The theoretical reference was based upon the works of authors such as Nóvoa, Garcia and Farias. The qualitative analysis showed that the PIBID has a strong potential for professional socialization, although it also shows contradictions within itself. It is now delineated in a perspective of rupture with technical and pragmatic processes, and affirms and relies on such processes. Establishing strong and comprehensive teacher education policies remains a challenge in the beginning of the 21st century.
\end{abstract}

\title{
Key words
}

Teacher's education; PIBID; Basic Education.

\section{Resumen}

En las últimas décadas abundan los análisis destacando la urgencia e importancia del establecimiento de vínculos más estrechos entre las instituciones formativas y la escuela. El Programa Institucional de Bolsa de Iniciação à Docência (PIBID) emerge en este escenario buscando estimular y valorizar la opción por el magisterio, iniciativa que en 2017 cumple diez años de su implantación. ¿Qué directrices demarcan ese programa? ¿Qué avances y contradicciones pueden ser identificados en la configuración del ejercicio de problematización de la temática de este trabajo? En el centro de las reflexiones están las directrices orientadoras y delineadoras del Programa, así como sus avances y contradicciones. El examen de la temática fue realizado con base en el análisis documental de las siguientes fuentes: referencias legales y edictos comunicados desde el inicio del PIBID. El acceso a los documentos se realizó mediante consulta directa al sitio de Coordenação de Aperfeiçoamento de Pessoal de Nível Superior (CAPES). La referencia teórica se apoyó en las formulaciones de autores como Nóvoa, García y Farías. El análisis cualitativo evidenció que el PIBID presenta un fuerte potencial de socialización profesional, aunque también se muestre con contradicciones, delineándose como una perspectiva de ruptura con procesos técnicos y pragmáticos y a veces afirmándose y apoyándose en tales procesos. Instituir políticas de formación docente fuertes y exhaustivas continúa siendo un desafío en este inicio del siglo XXI.

\section{Palabras clave}

Formación docente; PIBID; Educación Básica. 


\section{INTRODUÇÃO}

Que a formação de professores vive um fogo cruzado de críticas nas últimas décadas não é nenhuma novidade. Avultam análises destacando a urgência e a importância do estabelecimento de vínculos mais estreitos entre as instituições de formação e a escola pública. O Programa Institucional de Bolsa de Iniciação à Docência (PIBID) emerge nesse cenário visando estimular e valorizar a opção pelo magistério, iniciativa que, em 2017, registra dez anos de implantação. Quais diretrizes delineiam esse Programa? Que avanços e contradições podem ser identificados na configuração do PIBID desde sua primeira edição, em 2007? Essas inquietações dão corpo ao exercício de problematização da temática neste escrito.

Com efeito, as transformações que aconteceram nos decênios recentes em âmbito mundial na sociedade desenharam outras expectativas no âmbito da Educação, que passa a ser pensada como área estratégica para o desenvolvimento socioeconômico, sobretudo a partir dos anos 1990. Atribui-se ao professor e a sua formação significativa importância, o que denota a centralidade do tema na ordem social contemporânea. Ao mesmo tempo, as exigências e obrigações sobre os docentes se intensificam, levando, muitas vezes, a uma precarização de seus trabalhos, a um sufocamento e a um certo mal-estar docente, elementos que fragilizam a forma de se perceberem, repercutindo diretamente em sua atuação profissional.
Esse é um fenômeno que se caracteriza pela contradição: por um lado, o professor é chamado a ocupar novos espaços, sendo figura de destaque na valorização do ensino e da escola; de outra parte, não acontecem alterações substanciais nas condições de trabalho, salário e valorização de seu ofício. Alguns estudos (CANÁRIO, 1995, HARGREAVES, 1998) esclarecem que as reformas educacionais implantadas fracassaram por atribuírem ao professor o papel de mero executor, não promovendo mudanças efetivas no âmbito das práticas de ensino, da sala de aula. Na mesma perspectiva, Pimenta (2005) adverte para o fato de que a centralidade atribuída aos professores nas reformas educacionais brasileira trouxe novas responsabilidades aos docentes, mas aboliu do discurso temas como a valorização profissional, salário e condições de trabalho. Além disso, pouco se escuta o professor, sua fala quase sempre é abafada por especialistas que se arvoram em pensar as soluções para as conjunções de problemas que o docente vivencia no decurso de seu trabalho. Essa preocupação é manifesta por Nóvoa (2009, p. 27) ao assinalar a necessidade de maior presença pública dos professores e, ao mesmo tempo, advertir sobre "a distância que separa o excesso dos discursos da pobreza das práticas"; ou seja, fala-se muito sobre a formação de professores, mas as práticas pouco ou quase nada se alteram.

Contrapondo-se a essa tendência, o autor português argumenta em favor de uma formação de professores "cons- 
truída dentro da profissão", proposição assim sintetizada nas palavras do referido autor: "[...] isto é, baseada numa combinação complexa de contributos científicos, pedagógicos e técnicos, mas que tem como âncora os próprios professores, sobretudo os professores mais experientes e reconhecidos" (NÓVOA, 2009, p. 44). Uma formação que procura, como esclarece logo em seguida, "valorizar a componente práxica, a cultura profissional, as dimensões pessoais, as lógicas colectivas e a presença pública dos professores" (NÓVOA, 2009, p. 45).

Embora as formulações de Nóvoa considerem o contexto europeu, não há como negar a disseminação e o acolhimento de suas ideias no Brasil, onde as medidas para adequar a Educação aos interesses do mundo do trabalho se intensificaram após a promulgação da LDB n. 9.394/96 (BRASIL, 1996). É nesse momento que se assiste a um amplo investimento em políticas neoliberais, com destaque para a formação de professores, com iniciativas marcadas por uma lógica que reforça o caráter competitivo, a fragmentação e o pragmatismo na formação docente (FREITAS; VIEIRA; AGUIAR, 2008). Em decorrência das muitas exigências e demandas atribuídas ao professor, a realidade vivenciada por esse profissional é perpassada por crescente precarização do trabalho, persistência de problemas que estigmatizam a profissão docente e um profundo desencanto em relação à carreira docente. Embora, no plano do discurso político, essa formação seja alçada a importante estratégia de desenvolvimento social, acirram-se, nesse período, problemas históricos. Entre esses desafios, encontra-se a necessidade histórica e urgente de mobilizar a juventude para ingressar no magistério, sobretudo atrair jovens talentos.

É nesse âmbito que a Coordenação de Aperfeiçoamento de Pessoal de Nível Superior (CAPES), entidade originalmente instituída para cuidar do Ensino Superior e da pesquisa, passa a assumir, como seu atributo, a indução e o fomento da formação inicial e continuada de professores da Educação Básica, bem como o estímulo e a valorização do magistério em todos os níveis e modalidades de ensino (Lei n. 11.502/ 2007). O Programa Institucional de Bolsa de Iniciação à Docência (PIBID) desdobra-se como uma das ações adotadas com essa finalidade mediante o desenvolvimento de "oportunidades de criação e participação em experiências metodológicas, tecnológicas e práticas docentes de caráter inovador e interdisciplinar que busquem a superação de problemas identificados no processo de ensino-aprendizado" (Art. 3, item IV do Decreto n. 7.219). Seu desenho se assenta em ações formativas destinadas aos alunos de cursos de licenciaturas, envolvendo ainda o professor do Ensino Superior, nas funções de coordenador institucional, coordenador de área ou coordenador de gestão de processos educacionais; e o docente da Educação Básica, na função de professor supervisor, também identificado na documentação governamental referente 
ao Programa como "coformadores dos futuros docentes" (BRASIL, 2010b).

Desperta atenção um Programa que valoriza saberes de agentes com trajetórias de vida e de formação diversificadas, entre eles o professor da Educação Básica, que é chamado a atuar na linha de frente na formação de futuros colegas de profissão. As diretrizes norteadoras e delineadoras dessa expe- riência de formação, assim como seus avanços e contradições, estão no centro das reflexões registradas nesse escrito.

O exame da temática, de natureza teórico, foi realizado com suporte na análise documental das seguintes fontes: editais lançados desde o início do PIBID e referências legais sobre o programa, os quais estão detalhados nos Quadros 1 e 2.

\begin{tabular}{|c|c|}
\hline EDITAIS & A QUEM SE DESTINA \\
\hline Edital n. 01/2007 & Instituições Federais de Ensino Superior \\
\hline Edital n. 02/2009 & $\begin{array}{l}\text { Instituições Públicas de Educação Superior (IPES), federais e } \\
\text { estaduais }\end{array}$ \\
\hline Edital n. 18/2010 & $\begin{array}{l}\text { Instituições públicas municipais e comunitárias confessionais } \\
\text { e filantrópicas sem fins lucrativos }\end{array}$ \\
\hline $\begin{array}{l}\text { Edital conjunto n. } 2 / 2010 \\
\text { CAPES/SECAD }\end{array}$ & $\begin{array}{l}\text { Instituições que trabalham nos programas de formação de } \\
\text { professores Prolind e Procampo. }\end{array}$ \\
\hline Edital n. 1/2011 & Instituições públicas de Ensino Superior \\
\hline Edital n. 11/2012 & $\begin{array}{l}\text { Instituições de Ensino Superior públicas, } \\
\text { filantrópicas, confessionais ou comunitárias. }\end{array}$ \\
\hline Edital n. 61/2013 & Instituições públicas, comunitárias e privadas do ProUni \\
\hline $\begin{array}{l}\text { Edital n. } 66 / 2013 \text { PIBID/ } \\
\text { Diversidade }\end{array}$ & $\begin{array}{l}\text { IES públicas e privadas sem fins lucrativos que deverão } \\
\text { desenvolver atividades em escolas indígenas e do campo - } \\
\text { incluídas as escolas quilombolas, extrativistas e ribeirinhas } \\
\text { - da rede pública de ensino. }\end{array}$ \\
\hline
\end{tabular}

Quadro 1 - Editais do PIBID e público a quem se destina

Fonte: Elaboração própria

\begin{tabular}{|l|c|l|}
\hline \multicolumn{1}{|c|}{ REFERÊNCIAS LEGAIS } & DATA & \multicolumn{1}{c|}{ ASSUNTO } \\
\hline Portaria Normativa n. 38 & $12 / 12 / 2007$ & Institui o PIBID, no âmbito do MEC, da CAPES e do FNDE. \\
\hline Portaria n. 122 & $16 / 09 / 2009$ & Instituir, no âmbito da CAPES, o PIBID \\
\hline Portaria n. 72 & 09/04/2010 & Dá nova redação à Portaria que dispõe sobre o PIBID. \\
\hline Decreto n. 7.219 & 24/06/2010 & Lei que dispõe sobre o PIBID e dá outras providências \\
\hline Portaria n. 096 & $18 / 07 / 2013$ & Regulamenta o PIBID \\
\hline
\end{tabular}

Quadro 2 - Referências legais sobre o PIBID, contendo data e assunto.

Fonte: Elaboração própria 
Nas fontes utilizadas, tanto nos editais quanto nas referências legais, foram explorados os seguintes aspectos: os objetivos e princípios do PIBID, as instituições contempladas em cada edição e o desenho geral do programa, nesse último buscando identificar o foco de atenção das edições, os níveis e modalidade priorizados, a relação PIBID e estágio. A tessitura da análise adotou, como ponto de partida e de articulação desses elementos, os objetivos declarados tanto nas referências legais quanto nos editais, processo que possibilitou ir percebendo os avanços, as lacunas e as contradições em cada momento em que o PIBID foi se configurando enquanto uma ação de iniciação profissional à docência no país.

Acredita-se que examinar as alterações ocorridas na proposta do Programa nesses documentos desde 2007 permite evidenciar as compreensões e caminhos desenhados por essa iniciativa, possibilitando entender também o potencial dessa ação governamental na construção de rotas alternativas para a formação de professores no Brasil.

A adoção da análise documental como caminho metodológico apoiou-se no entendimento de que os documentos, ao seu modo, efetivamente 'falam', sendo, por isso, um indício imediato dos acontecimentos e das concepções que Ihe deram corpo, especialmente quando se tem como foco uma política, como é o caso do PIBID. A análise considerou, ainda, que o documento "é apenas o ponto de partida de um percurso que necessita ser construído teoricamente, que não está dado na natureza inerte do papel nem revelado de antemão na letra da lei [...]", pois que "não é concreto no sentido imediato, senão se constitui, pela descoberta das relações, no processo reflexivo" (FARIAS; BEZERRA, 2011, p. 52).

\section{PIBID: PROPÓSITOS E DELINEAMENTOS GERAIS}

O PIBID foi implementado, em nível nacional, através do edital MEC/ CAPES/FNDE pela Portaria Normativa n. 38/2007, com vistas a fomentar a iniciação à docência de estudantes das instituições federais de Educação Superior e preparar a formação de docentes em nível superior, em cursos de licenciatura presencial plena, para atuar na Educação Básica pública. O Programa contempla licenciandos, professores da Educação Básica e professores do Ensino Superior.

O primeiro edital do PIBID foi lançado em 2007, e os projetos institucionais tiveram início no ano de 2008. 0 Programa, em seu início, contemplava somente as Universidades e Institutos Federais e, a partir do ano de 2009, foram incluídas as instituições de ensino superior (IES) estaduais, municipais e instituições comunitárias, confessionais e filantrópicas e privadas sem fins lucrativos. Desde 2013, também participam do programa alunos do Programa Universidade para Todos (ProUni) das instituições privadas com fins lucrativos. 
De acordo com os últimos dados apresentados pela CAPES ${ }^{1}$, o PIBID até 2014 , contava com 26 projetos na região Centro-Oeste do país; 66 na região Nordeste; 32 na região Norte; 117 no Sudeste e 72 na região Sul do Brasil. A iniciativa oferece um total de $\mathbf{9 0 . 2 5 4}$ bolsas, distribuídas entre licenciandos, professores supervisores, coordenadores de área de gestão, coordenadores de área e coordenação institucional. Em termos quantitativos, O PIBID tornou-se o programa "que mais cresceu" na CAPES, "ultrapassando inclusive a oferta de programas já consolidados de formação científica, como o Programa Institucional de Bolsa de Iniciação Científica (PIBIC), do CNPq", informam Cavalcante e Farias (2016, p. 103). No que se refere aos recursos designados para essa iniciativa, as autoras sublinham que esses podem "ser considerado alto se levado em consideração que os investimentos em ações dessa natureza eram praticamente inexistentes" (CAVALCANTE; FARIAS, 2016, p. 103). O volume de recursos destinado ao programa saltou de $\mathrm{R} \$ 20.041 .950,00$, em 2009, para R\$287.900.596,00, em 2013.

Para dimensionar o "alcance dessa iniciativa no território nacional", porém, vale lembrar a ponderação de Carvalho et al. (2015, p. 21) ao recorrer a dados do ensino superior divulgados pelo INEP:

[...] em 2013 o Brasil possuía 301 instituições públicas de en-

\footnotetext{
${ }^{1}$ Disponível em: <http://www.capes.gov.br/educacao-basica/capespibid/relatorios-e-dados>.
}

sino superior que concorriam com 2.090 instituições mantidas pela iniciativa privada. Essas instituições atenderam, no ano de 2013 , em seus cursos de licenciatura, um universo de 1.374.174 alunos matriculados e, nesse mesmo ano, formaram um total de 201.353 novos professores de diversas áreas de ensino, sendo 71.149 egressos das instituições públicas e 130.204 das instituições privadas.

Os dados contextualizam o núcleo duro das críticas dirigidas a esse programa, as quais realçam o caráter excludente dessa ação ao não contemplar todos os discentes dos cursos de licenciatura. Para melhor compreender tais análises cabe detalhar os objetivos que regem o PIBID. A Portaria Normativa que o institui em âmbito nacional assim define seus objetivos:

I - incentivar a formação de professores para a educação básica, especialmente para o ensino médio; II - valorizar o magistério, incentivando os estudantes que optam pela carreira docente; III - promover a melhoria da qualidade da educação básica; IV - promover a articulação integrada da educação superior do sistema federal com a educação básica do sistema público, em proveito de uma sólida formação docente inicial; $\vee$ - elevar a qualidade das ações acadêmi- 
cas voltadas à formação inicial de professores nos cursos de licenciaturas das instituições federais de educação superior (BRASIL, CAPES, 2007).

O PIBID exprime como proposição o fortalecimento da profissão docente e evidencia a necessidade de maior atenção sobre a formação inicial de professores que se dá nas instituições de Ensino Superior, mas restringe sua primeira edição às instituições federais, sejam estas universidades ou institutos.

Os objetivos do PIBID são amplos, incluindo, entre outros, valorização do magistério, melhoria na qualidade da Educação Básica, articulação universidade e escola, elevação da qualidade das ações acadêmicas. É possível identificar o fato de que o Programa focaliza, em seus objetivos, problemas crônicos vivenciados na formação de professores, a exemplo da articulação teoria e prática que, mesmo não mencionada explicitamente, está subliminarmente expressa nos objetivos IV e V da Portaria n. 38/2007. De certo modo, eles estão associados ao enfrentamento de questões complexas da Educação nacional, os quais incidem sobre a qualidade da Educação, como aponta o objetivo III. É difícil pensar, contudo, que mudanças profundas possam acontecer na qualidade da educação se não houver investimentos substanciais em outros aspectos relacionados aos problemas que sobre ela incidem, como a Educação Superior, o estágio curricular e as condições de trabalho e de salários dos docentes.
Os objetivos elencados na Portaria Normativa n. 38/2007 também denotam cuidado com a formação dos professores para o Ensino Médio, como é possível perceber no objetivo I, sobretudo nas áreas da Matemática, Física, Química e Biologia. De fato, a baixa atratividade da profissão de professor acarreta uma crescente e inquietante evasão docente nas escolas de Educação Básica. O reduzido número de professores que atua nesse nível de ensino é uma realidade reconhecida há muito tempo.

Outro aspecto ressaltado nos objetivos refere-se à aproximação da universidade em relação à escola, quando objetiva promover a articulação integrada da Educação Superior com a Educação Básica pública tendo por fim a melhoria na formação inicial dos cursos de licenciatura. Aqui se registra uma crítica ao modelo formativo universitário vigente, corroborando estudos que indicam a necessidade de novas configurações para a formação profissional de docentes em nível superior. Este é o entendimento de Garcia (1999), para quem a inovação mais relevante no campo da formação docente demanda reformular a relação entre a universidade e a escola. $O$ autor é incisivo na asserção de que é preciso desenvolver relações de colaboração entre as instituições e que somente assim será possível contribuir para superar o tradicional individualismo que caracteriza o aprender a ensinar. De acordo com o Relatório de Gestão do PIBID - 2009 a 2013 (BRASIL, CAPES, 2013), a modificação e a constituição de uma nova cultura 
educacional que se pretende alcançar com o PIBID pautam-se em pressupostos teórico-metodológicos que articulam teoria-prática, universidade-escola e formadores-formandos, permitindo inferir que o Programa considera como eixo orientador da formação a interação dos distintos sujeitos e saberes sobre a docência.

Por certo, aproximar a universidade da escola é um dos caminhos para a promoção da unidade teoria e prática, porém, não garante, por si, a efetivação, sendo necessário investir em outros aspectos que também incidem sobre a formação de professores e a qualidade da Educação, e, principalmente, romper com a visão dicotômica de que a universidade é responsável pela produção do conhecimento (teoria), e à escola cabe o papel de aplicar e reproduzir o conhecimento (prática).

O Edital 2007, que convoca as instituições federais de Educação Superior a apresentarem propostas de projetos institucionais de iniciação à docência, é coerente com os objetivos explicitados na Portaria Normativa n. 38/2007, mas os amplia, incluindo quatro novos objetivos, sendo assim definidos:

F- Estimular a integração da educação superior com a educação básica no ensino fundamental e médio, de modo a estabelecer projetos de cooperação que elevem a qualidade do ensino nas escolas da rede pública; G- Fomentar experiências metodológicas e práticas docentes de caráter inovador, que utilizem recursos de tecnologia da informação e da comunicação, e que se orientem para a superação de problemas identificados no processo ensino-aprendizagem; H- Valorização do espaço da escola pública como campo de experiência para a construção do conhecimento na formação de professores para a educação básica; I- Proporcionar aos futuros professores participação em ações, experiências metodológicas e práticas docentes inovadoras, articuladas com a realidade local da escola. (BRASIL. CAPES, 2007).

Os objetivos do Edital 2007 do PIBID enfatizam a importância da escola no processo formativo e chamam a atenção para a necessidade de inovações pedagógicas que favoreçam a melhoria dos processos de ensino e de aprendizagem. A ideia de inovação aparece de modo enfático nos objetivos, empregada recorrendo sobretudo ao "efeito mobilizador que o termo tem sobre os indivíduos, ensejando uma imagem proativa do mesmo" (FARIAS, 2002, p. 82). O termo inovação, há décadas permeia o universo educacional. Inovação, de forma geral, significa o ato ou efeito de inovar ou, como sugere Farias (2006, p. 52), "a indicação de algo novo, de novidade, é a primeira ideia que a palavra inovação suscita". Relacionado à Educação, o termo adquire significados diferentes de acordo com o tempo e o 
contexto, constituindo uma polissemia no vocábulo.

É importante ressaltar o fato de que nem sempre a inovação resulta em mudança. Esta depende do envolvimento dos sujeitos. Mudar é complexo, principalmente porque envolve diretamente a dimensão do humano, mobilizando capacidades intelectuais e emocionais (FARIAS, 2002). Na perspectiva de Rosa (1998), "mudar é muito mais do que inovar, posto que entre esses dois termos, não existe, a rigor, vínculo necessário". 0 novo envolve quase sempre receio e ansiedade. Não basta anunciar a inovação como propósito de um programa para que alterações substanciais aconteçam, especialmente no caso da profissão e formação de professores, porquanto é preciso que valores, atitudes e modos de pensar a profissão sejam afetados. Concordamos com Nóvoa (1995, p. 8) quando diz: "A inovação não se decreta. $A$ inovação não se impõe. $A$ inovação não é um produto. É um processo. Uma atitude. É uma maneira de ser e estar na educação". Ademais, ao falarmos em inovação educacional, não é possível situá-la como responsabilidade exclusiva do professor.

Essa compreensão dos vínculos entre inovação como indutor de mudanças nos parece pertinente para olhar o PIBID e seus objetivos. Com efeito, os objetivos propostos no Edital 2007 reafirmam a importância da prática pedagógica inovadora, porém não fazem referência à necessidade de pensar sobre esta prática. Aproximar a teoria da prática é um discurso repetido tanto por estudiosos da temática como pelo senso comum, o que pressupõe as distâncias entre a formação inicial e a vivência na escola serem encurtadas, se reconheça a escola como espaço formativo, possibilitando a interação e a troca de saberes dos diversos sujeitos envolvidos. É importante, no entanto, que a relação teoria e prática seja equilibrada e que nenhum dos aspectos se sobreponha ao outro. A prática precisa ser reflexiva, pois, como adverte Nóvoa (2007, p.16), "não é a prática que é formadora, mas sim a reflexão sobre a prática".

Em torno ainda dessa temática, merece registro o debate entre PIBID e Estágio Supervisionado, o qual alcança visibilidade nos eventos e produções recentes no campo da Didática e da Formação de Professores. No seu desenho inicial, conforme a Portaria $n$. $38 / 2007$, o PIBID assume o caráter de estágio não curricular, o que é assim explicitado: "parte do período do estágio de iniciação à docência deverá ser cumprida em escolas com baixos Índices de Desenvolvimento da Educação Básica - IDEB e em escolas com baixas médias no Exame Nacional de Ensino Médio ENEM" (Art. 3). Nos documentos que se seguiram a este, o termo estágio é suprimido. Sem dúvida, as interfaces do PIBID com o estágio curricular são muitas, uma vez que ambos possibilitam a iniciação à profissão docente, contudo, originalmente, o PIBID surge como atividade distinta do estágio curricular, que exprime legislação própria, inserido 
em atividade acadêmica alinhada a um fluxo curricular específico aos cursos de graduação.

O questionamento em torno dessas duas ações de articulação universidade e escola, teoria e prática, reside especialmente em seu significado como política no campo da formação de professores, naquilo que ela revela. Noutros termos: por que não fortalecer os cursos de licenciatura por meio de seus projetos político-pedagógicos, assegurando- Ihe o suporte financeiro aportado no PIBID? A indagação nos faz ponderar sobre a possibilidade de uma proposta integradora dos propósitos dessas duas instâncias (CAPES e universidades), discussão por certo fértil, mas que precisa se intensificar, principalmente porque as fragilidades vivenciadas em ambas as ações não podem ser ignoradas, uma vez que refletem as ambiguidades e lacunas da política educacional destinada à formação de professores. A nosso ver, esse diálogo é possível e, certamente, poderia potencializar os efeitos que a articulação mais orgânica entre universidade e escola desponta, reconhecendo-a como espaço essencial de formação, de geração e aprendizagem de saberes e de identificação com a futura profissão (PIMENTA; LIMA, 2008).

Nos dispositivos subsequentes sobre o PIBID, como salientamos, a referência ao seu caráter de estágio não curricular é silenciada. É o que se verifica, por exemplo, na Portaria n. 122, de 16 de setembro de 2009, que respalda o Edital 2009 do PIBID e trouxe modificações significativas nos objetivos do Programa. A ênfase no Ensino Médio desaparece, estendendo-se a todos os subníveis de ensino e áreas complementares. Ao princípio da inovação acrescentam-se a interdisciplinaridade e o foco no desempenho da escola em avaliações de larga escala (Inciso V, 10 parágrafo).

O conceito de interdisciplinaridade, assim como de inovação, é complexo e denota compreensões diferenciadas. Para alguns significa romper com uma concepção tradicional de Educação que compartimentaliza o conhecimento, enquanto outros a entendem como a interação das diversas disciplinas. Segundo Fazenda (1979, p. 108) "interdisciplinaridade não se ensina, não se aprende, apenas vive-se, exerce-se e por isso exige uma nova pedagogia, a da comunicação".

O foco sob o desempenho escolar nas avaliações de larga escala (Provinha Brasil, Prova Brasil, SAEB, ENEM) reforça a preocupação governamental com os pífios resultados dos alunos nas avaliações externas, evidenciando, por conseguinte, o entendimento de que o fato de melhorar a qualidade da formação docente está diretamente associado ao propósito de melhorar a qualidade do ensino e da aprendizagem, em geral, reduzida a noção de desempenho. Mesmo reconhecendo que fomentar a aprendizagem é o fim último da escolarização, não é possível desconsiderar as críticas aos processos avaliativos de larga escala. Em geral, elas alertam para o estreitamento da noção de desempenho em relação ao conceito de aprendizagem, 
compreendida como expressando outras dimensões além do cognitivo. Também suscitam pensar na cobrança de resultados que vem sendo feita, de modo direto à figura do professor, no sentido de os estudantes obterem melhores resultados nas avaliações. Como consequência, observa-se maior controle do exercício profissional, sobrecarga de trabalho, atribuindo-se ao professor uma responsabilidade quase exclusiva pelos resultados a serem alcançados. Esse indicativo, por certo, denota o alinhamento do PIBID como política atenta à orientações de cunho neoliberal que privilegiam o resultado e, no que concerne à formação de professores, há de cuidar para que tais propósitos não fortaleçam orientações de bases pragmáticas.

No ano de 2010, um novo Edital foi publicado, e este traz os mesmos objetivos do anterior, registrando alterações somente quando remete às instituições participantes. Nesse edital, em vez de se referir às "instituições públicas de ensino superior", o texto se reporta a universidades e centros universitários comunitários. Ainda no mesmo ano, foi editada a Portaria n. 72, de 9 de abril, que traz novas orientações para o PIBID. Os objetivos propostos no último edital foram objeto de pequenas alterações. Compilam-se os primeiros objetivos que tratam do incentivo à formação de professores e valorização do magistério, substituindo a palavra incentivar, que se referia ao objetivo "incentivar os estudantes que optam pela carreira docente", pelo termo "apoiar". Os demais objetivos permanecem sem alterações. Também naquele ano foi aprovado o Decreto n. 7.219, de 24 de junho de 2010, que altera, em parte, os objetivos do Programa. Destaca como um dos objetivos específicos a valorização do magistério (Inciso III) e acrescenta como objetivo "contribuir para a articulação entre teoria e prática necessárias à formação dos docentes, elevando a qualidade das ações acadêmicas nos cursos de licenciatura". (Inciso VI). Outro aspecto modificado diz respeito a excluir a recomendação de inserção dos licenciandos em escolas participantes de avaliações de larga escala. Mais uma vez os objetivos reforçam a ideia de que a valorização do magistério passa pelo fortalecimento da formação inicial dos professores. O novo objetivo proposto enfatiza a importância da relação teoria e prática, pressuposto latente, mas não explicitado até então.

Os Editais de 2011, 2012 e 2013 não trazem em suas escritas os objetivos do Programa, presumindo que se orientam pelo disposto no Decreto $n$. 7.219/2010. No ano de 2013, a Portaria n. 096, de 18 de julho, encerra o regulamento do PIBID. Os objetivos do PIBID expressos nesse documento estão bem próximos daqueles descritos no Decreto de 2010, com modificação apenas no último objetivo, que traz para o texto dicções como cultura escolar, reflexão e saberes, não mencionados, até então, e de suma importância quando se pensa uma formação robusta, não pragmatista e de caráter emancipatório. 
De acordo com a Portaria n. 096/2013, os objetivos do PIBID ficam assim definidos:

I-incentivar a formação de docentes em nível superior para a educação básica; II - contribuir para a valorização do magistério; III - elevar a qualidade da formação inicial de professores nos cursos de licenciatura, promovendo a integração entre educação superior e educação básica; IV-inserir os licenciandos no cotidiano de escolas da rede pública de educação, proporcionando-lhes oportunidades de criação e participação em experiências metodológicas, tecnológicas e práticas docentes de caráter inovador e interdisciplinar que busquem a superação de problemas identificados no processo de ensino-aprendizagem; $\mathrm{V}$ - incentivar escolas públicas de educação básica, mobilizando seus professores como co-formadores dos futuros docentes e tornando-as protagonistas nos processos de formação inicial para o magistério; VI contribuir para a articulação entre teoria e prática necessárias à formação dos docentes, elevando a qualidade das ações acadêmicas nos cursos de licenciatura; VII - contribuir para que os estudantes de licenciatura se insiram na cultura escolar do magistério, por meio da apropriação e da reflexão sobre instrumentos, saberes e peculiaridades do trabalho docente. (BRASIL. CAPES, 2013).

Embora não esteja expresso no texto, o objetivo VII aponta para a importância de se fortalecer uma identidade profissional quando reitera a necessidade da apropriação e da reflexão sobre instrumentos, saberes e peculiaridades do trabalho docente para o aprendizado da cultura escolar pelos licenciandos, futuros professores. Por certo, as transformações ocorrentes no contexto social, político, econômico e institucional reverberam na pessoa do professor e em seu fazer profissional, exigindo dos processos formativos maior atenção no que se refere à constituição de sua identidade como docente. O objetivo descrito também expressa respeito e valorização à cultura escolar. A formação de professores precisa estar consorciada aos elementos da cultura profissional e do lugar de trabalho. Por conseguinte, pensar no desenvolvimento docente é investir em processos colaborativos, que privilegiem aspectos técnicos, mas também afetivos e reflexivos, que percebam o professor como um ser inserido em uma cultura, em determinado tempo, protagonista de sua história, um ser de possibilidades. Essa perspectiva também expressa a necessidade de o licenciando pautar sua atuação na reflexão, aspecto apontado na literatura como essencial para o desenvolvimento do trabalho docente.

Os saberes docentes, conforme é destacado no texto da Portaria n. 
096/2013, constituem rol de elementos significativos e que precisam ser considerados nos processos formativos. Tardif (2012) expressa a noção de que, em essência, o professor tem o saber como elemento inerente ao seu trabalho, no entanto, nem sempre a relação entre os professores e os saberes constitui um vínculo fácil. Ainda de acordo com o autor, "a relação que os professores mantêm com os saberes é a de transmissores, de portadores ou de objetos de saber, mas não de produtores de um saber ou de saberes que poderiam impor como instância de legitimação social de sua função e como espaço de verdade de sua prática" (TARDIF, 2012, p. 40). Nesse sentido, é preciso que os professores se apropriem de seus saberes, que reconheçam e constituam novos saberes e não apenas reproduzam aqueles determinados por outros. Refletir sobre os saberes docentes é, portanto, uma prática necessária e fundamental. .

Ainda no ano de 2013, foi lançado o Edital PIBID Diversidade, objetivando selecionar projetos institucionais que visem ao aperfeiçoamento da formação inicial de professores para o exercício da docência nas escolas indígenas e do campo. Em relação aos objetivos propostos nesse Edital, houve a permanência de seis objetivos previstos no Edital anterior, incluindo no texto apenas referência a quem se destinam as ações (comunidades indígenas e do campo).

Nos documentos antecedentes a esse, um dos objetivos faz referência ao professor como "coformador" dos licen- ciandos. Nesse edital, o termo é suprimido, e a ênfase recai na própria escola de Educação Básica. Três novos objetivos foram acrescidos. Um deles destaca a investigação docente com vistas à intervenção pedagógica no desenvolvimento de metodologias específicas. Pela primeira vez, os documentos do PIBID fazem referência explícita à importância da investigação para repensar os processos de ensino e de aprendizagem. Nesse mesmo sentido, outro objetivo proposto enfatiza a importância da reflexão crítica das atividades didático-pedagógicas para o fortalecimento da escola.

Até então, os editais anteriores se arvoravam em garantir a vivência da prática pedagógica, sem nenhuma referência direta aos processos reflexivos vivenciados neste contexto, o que colocava em questão a perspectiva proclamada sobre a unidade teoria prática, uma vez que uma prática sem reflexão é vazia de significados. Não basta apenas, no entanto, fazer referência ao termo, pois necessário se faz entender como a reflexão crítica vem se efetivando no desenvolvimento das ações do PIBID. Um dos objetivos acrescentados nesse edital reforça a necessidade de considerar, no processo formativo, as diferenças culturais e interculturais do País e como estas impactam no trabalho pedagógico, objetivo que deve ser perseguido em qualquer processo formativo, não apenas nesse específico, afinal, o Brasil é um país caracterizado apela diversidade cultural, o que não pode ser ignorado, mas respeitado e refletido. 
As alterações na redação dos objetivos do Programa ao longo dos anos de sua vigência evidenciam intenções de aprimoramento sem, contudo, perder de vista propósitos como a valorização do magistério, a inserção dos licenciandos na escola, o incentivo à formação dos docentes, a elevação da qualidade da formação inicial e a promoção da integração entre Educação Superior e Educação Básica. Nesse sentido, evidenciam o PIBID como uma via com forte potencial de socialização profissional, embora também se mostre como uma política perpassada por contradições, ora apresenta-se numa perspectiva de ruptura com processos técnicos e pragmáticos, ora afirma e se apoia em tais processos.

\section{DESAFIOS QUE PERMANECEM - À GUISA DE CONSIDERAÇÕES FINAIS}

A compreensão de como os objetivos do PIBID foram delineados desde que o Programa se iniciou permitiu perceber que este esteve atento à realidade em que foi se concretizando, ampliando as instituições envolvidas e os sujeitos contemplados. Evidenciou, também, que, ao mesmo tempo em que incluiu na sua proposta novos elementos, manteve em suas diversas edições a compreensão da escola como espaço de formação, a articulação de saberes de sujeitos em distintos estádios de desenvolvimento e a articulação teoria e prática.

O Programa surge no intuito de resolver problemas crônicos da Educação
Brasileira, principalmente no que concerne à formação inicial de professores e ao fortalecimento da profissão docente. Também inclui em seus objetivos, a meIhoria na qualidade da Educação Básica, articulação universidade e escola e elevação da qualidade das ações acadêmicas. Em seus propósitos, intenta promover rupturas com modelos formativos de base instrumental, assumindo princípios como a articulação teoria-prática; inserção precoce de licenciandos na escola, cooperação entre sujeitos em distintos estádios de desenvolvimento profissional (professores da universidade, da escola e licenciandos). Ao mesmo tempo, revela em seus objetivos alinhamento com princípios mais pragmáticos, quando expressa preocupação com resultados quantitativos dos alunos.

O PIBID traz objetivos amplos que, certamente, extrapolam o alcance de um programa, necessitando que outras mudanças substanciais sejam feitas em relação às fragilidades apontadas - desafio que permanece e se agrava ante o novo panorama vivenciado pela Educação em nosso País.

Inúmeros, certamente, são os desafios de um programa da natureza do PIBID. Enxergar uma perspectiva problematizadora para as reais necessidades da escola, alunos e professores é condição básica para a efetivação do Programa, considerando a intencionalidade expressa, na documentação governamental (Portaria Normativa n. 38/2007), de valorizar o magistério e de promover a melhoria da qualidade da Educação 
Básica, dentre outros objetivos propostos. Pondera, ainda, ser necessária uma política ampla e consoante aos anseios reais da escola, considerando que mudanças no âmbito da prática de ensino e da aprendizagem dos alunos reclamam a adesão dos professores. Igualmente adverte sobre o caráter complementar e restrito do PIBID, que não contempla todos os licenciandos, de modo que não pode ser considerada como solução para os problemas relacionados à qualidade da Educação, muito menos à formação de professores.

Entende-se também que os propósitos declarados do PIBID na documentação examinada denunciam a fragilidade da formação docente no Brasil, especialmente as lacunas da formação inicial de nível superior, responsabilidade histórica das universidades. Por outro lado, compreende-se o fato de que instituir políticas fortes e abrangentes é expresso como desafio que permanece neste início de século XXI. O PIBID é um Programa que não chega a todos os alunos das licenciaturas, não sendo possível pensar soluções para problemas complexos, como a formação docente numa perspectiva de exclusão ou mesmo de uma "inclusão excludente". Concordamos com Veiga (2010), quando acentua que é preciso pensar em políticas públicas que visem não apenas aos imediatismos, mas que beneficiem as múltiplas facetas da profissão docente: formação inicial, continuada, valorização do magistério, salário, carreira etc.

$O$ atual cenário econômico e político do Brasil, não se mostra favorável para a formação docente, sendo a permanência do PIBID algo incerto. Embora a atual conjuntura se mostre desfavorável e desanimadora, não podemos deixar de crer em nosso poder de transformação e resistência. É preciso, pois, continuar em busca daquilo que acreditamos e lutando em defesa da Educação e dos professores de nosso País. Isso implica, também, defender a necessidade de políticas que, assim como o PIBID, valorizem o professor, a escola, os saberes docentes, o intercâmbio da universidade e escola, a articulação entre pares e olhe para o professor em sua inteireza. Enfim, que faça uma articulação social, aproximando universidade e escola básica; que reconheça a universidade e a escola como lugar de formação e que entenda o professor como ser concreto e singular, 0 que favorece ricas transformações para os sujeitos envolvidos.

\section{REFERÊNCIAS}

BRASIL. CAPES. Portaria n. 096, de 18 de julho de 2013. Regulamento do Programa Institucional de Bolsa de Iniciação à Docência. Diário Oficial da União, Brasília, p. 11, jul. 2013. Seção 1.

. Ministério da Educação/Conselho Nacional de Educação. Edital n. 61/2013. MEC/ CAPES/ FNDE. Disponível em: <http://www.capes.gov.br/ _. Acesso em: 5 jun. 2015. 
. Ministério da Educação/Conselho Nacional de Educação. Edital n. 066/2013. MEC/ CAPES/ FNDE. Disponível em: <http://www.capes.gov.br>. Acesso em: 5 jun. 2015.

. CAPES. Portaria n. 72, de 9 de abril de 2010. Dá nova redação a Portaria que dispõe sobre o Programa Institucional de Bolsa de Iniciação à Docência - PIBID, no âmbito da CAPES. Diário Oficial da União, Brasília, p. 26, abr. 2010a. Seção 1.

. Decreto n. 7.219, 24 de junho de 2010. Dispõe sobre o Programa Institucional de Bolsa de Iniciação a Docência-PIBID e dá outras providências. Diário Oficial da União, Brasília, p. 4-5, jun. 2010b. Seção 1.

. Ministério da Educação/Conselho Nacional de Educação. Edital n. 18/2010. MEC/ CAPES/FNDE PIBID Municipais e Comunitárias. Disponível em: $\leq$ http://www.capes.gov. br/>. Acesso em: 5 jun. 2015.

. Ministério da Educação/Conselho Nacional de Educação. Edital Conjunto $n$. 002/2010/CAPES/SECAD-MEC-PIBID Diversidade. Disponível em: $\leq$ http://www.capes.gov. $\mathrm{br} />$. Acesso em: 5 jun. 2015.

. CAPES. Portaria n. 122, de 16 de setembro de 2009. Dispõe sobre o PIBID - Programa Institucional de Bolsa de Iniciação à Docência, no âmbito da CAPES. Diário Oficial da União. Brasília, p. 91, set. 2009. Seção 1.

. Ministério da Educação/Conselho Nacional de Educação. Edital n. 02/2009. MEC/ CAPES/FNDE. Disponível em: shttp://www.capes.gov.br/>. Acesso em: 5 jun. 2015.

. CAPES. Portaria Normativa n. 38, de 12 de dezembro de 2007. Dispõe sobre o PIBID - Programa Institucional de Bolsa de Iniciação à Docência, no âmbito da CAPES. Diário Oficial da União. Brasília, p. 39, dez. 2007. Seção 1.

. Ministério da Educação/Conselho Nacional de Educação. Edital n. 01/2007. MEC/ CAPES/FNDE. Disponível em: Shttp://www.capes.gov.br/>. Acesso em: 5 jun. 2015.

. Decreto n. 2.134, de 24 de janeiro de 1997. Regulamenta o art. 23 da Lei n. 8.159, de 8 de janeiro de 1991, que dispõe sobre a categoria dos documentos públicos sigilosos e o acesso a ele, e dá outras providências. Diário Oficial da República Federativa do Brasil, DF, n. 18, p. 1435-1436, jan. 1997. Seção1.

. Ministério da Educação. Lei n. 9.394, Diretrizes e Bases da Educação Nacional. Brasília, 1996. Diário Oficial da União, Brasília, p. 27833, dez.1996. Seção 1.

. Ministério da Educação/Conselho Nacional de Educação. Edital n. 01/2011. MEC/ CAPES/ FNDE. Disponível em: <http://www.capes.gov.br/>. Acesso em: 5 jun. 2015.

. Ministério da Educação/Conselho Nacional de Educação. Edital n. 011/2012. MEC/ CAPES/ FNDE. Disponível em: <http://www.capes.gov.br/>. Acesso em: 5 jun. 2015.

CANÁRIO, R. Os estudos sobre a escola: problemas e perspectivas. In: BARROSO, João. (Org.). O estudo da escola. Portugal: Porto Editora, 1995. p. 125-150. 
CARVALHO, J. do P. F. de et al. Programa Institucional de Bolsa de Iniciação à Docência: apontamentos sobre editais e formação de professores da Educação Básica. In: FARIAS, I. M. S.; JARDILINO. J. R. Lima; SILVESTRE, M. A. (Org.). Aprender a ser professor: aportes de pesquisa sobre o PIBID. Jundiaí, SP: Paco Editorial, 2015. p. 15-30.

CAVALCANTE, M. M. da S.; FARIAS, I. M. S. de. A formação e a identificação com a profissão de egressos de programa de inserção na docência. Educação em Perspectiva, Viçosa, MG, v. 6, n. 1, p. 97-122, jan./jun. 2016.

DIRETORIA DE FORMAÇÃO DE PROFESSORES DA EDUCAÇÃO BÁSICA (DEB). Relatório de Gestão 2009-2013. Brasília: CAPES, 2013. 328 p. Disponível em: $\leq$ https://www.capes.gov. br/images/stories/download/bolsas/2562014-relatrorio-DEB-2013-web.pdf>. Acesso em: 12 abr. 2015

FARIAS, I. M. S. de. Inovação e mudança: implicações sobre a cultura dos professores. 2002. 260f. Tese (Doutorado em Educação) - Universidade Federal do Ceará, Fortaleza, CE, 2002. . Inovação, mudança e cultura docente. Brasília: Líber Livro, 2006.

FARIAS, I. M. S. de; BEZERRA, J. E. B. Do documento ao documento: recompondo seu lugar histórico. In: NÓBREGA-THERRIEN, S. M.; FARIAS, I. M. S. de; NUNES, J. B. C. Pesquisa científica para iniciantes: caminhando no labirinto. Fortaleza, CE: EdUECE, 2011. p. 43-54. FAZENDA, I. Integração e interdisciplinaridade no ensino brasileiro. São Paulo: Loyola, 1979. FREITAS, H. C. L. de; VIEIRA, J. D.; AGUIAR, M. A. da S. Verbos intransitivos para uma política pública: formar, valorizar, profissionalizar. Revista Retratos da escola, Brasília, v. 2, n. 2/3, p. 15-27, jan./dez. 2008.

GARCIA, C. M. Formação de professores: para uma mudança educativa. Porto, Portugal: Porto Editora, 1999.

HARGREAVES, A. Os professores em tempo de mudança. Porto: Edições ASA, 1998.

NÓVOA, A. Professores, imagens do futuro presente. Lisboa, Portugal: EDUCA, 2009.

Desafios do trabalho do professor no mundo contemporâneo. Palestra ministrada no Sindicato dos Professores de São Paulo (SINPRO-SP), em 2007. Disponível em: <http:// www.sinpro.org.br/arquivos/novoalivreto_novoa.pdf>. Acesso em: 10 abr. 2014. . Profissão professor. Porto: Porto Editora, 1995.

PIMENTA, S. G. Professor reflexivo: construindo uma crítica. In PIMENTA, S. G.; GHEDIN, E. (Org.). Professor reflexivo no Brasil: gênese e crítica de um conceito. São Paulo: Cortez, 2005. p. 17-52.

PIMENTA, S. G.; LIMA, M. S. L. Estágio e docência. 3. ed. São Paulo: Cortez, 2008. (Docência em Formação).

ROSA, S. S. da. Construtivismo e mudança. 6. ed. São Paulo: Cortez, 1998. (Coleção Questões da Nossa Época, v. 29). 
TARDIF, M. Saberes docentes e formação profissional. 13. ed. Petrópolis, RJ: Vozes, 2012. UNIVERSIDADE ESTADUAL DO CEARÁ (UECE/PIBID). Proposta Institucional. $A$ vida docente na escola: aprender e ensinar pela pesquisa. Fortaleza, 2009, 23p. Disponível em: <http:// www.uece.br/pibid/dmdocuments/Proposta\%20Institucional\%20UECE\%202011.pdf>. Acesso em 05/06/2015.

VEIGA, I. P. A.; QUIXADÁ VIANA, C. M. Q. Formação de professores: um campo de possibilidades inovadoras. In: VEIGA, I. P. A. V.; SILVA, E. F. da (Orgs.). A escola mudou. Que mude a formação de professores! Campinas, São Paulo: Papirus, 2010. p. 13-34.

\section{Sobre as autoras:}

Giovana Maria Belém Falcão: Doutoranda em Educação pelo Programa de Pós-graduação da Universidade Estadual do Ceará, Mestre em educação pela Universidade Federal do Ceará, Graduada em Psicologia pela Universidade Federal do Ceará, Professora Assistente da Universidade Estadual do Ceará, do curso de Pedagogia, área Psicologia da Educação. Integrante do Grupo de Pesquisa Educação, Cultura e Sociesdade (EDUCAS). Bolsista do Observatório Desenvolvimento Profissional Docente e Inovação Pedagógica, iniciativa apoiada pelo Programa Observatório da Educação-OBEDUC/CAPES-Projeto em rede UECE, UFOP, UNIFESP-Guarulhos (Edital 2012). E-mail: giovana.belem@yahoo.com.br

Isabel Maria Sabino de Farias: Doutora em Educação Brasileira (UFC), com estudos de pós doutoramento em Educação na Universidade de Brasília (UNB), licenciada em Pedaogia. Professora do Centro de Educação e coordenadora do Programa de Pós-Graduação em Educação (PPGE) da Universidade Estadual do Ceará. Lider do Grupode Pesquisa Educação Cultura Escolar e Sociedade(EDUCAS). Coordenadora do Observatório Desenvolvimento Profissional Docente e Inovação Pedagógica, iniciativa apoiada pelo Programa Observatório da Educação-OBEDUC/CAPES- Projeto em rede UECE, UFOP, UNIFESP-Guarulhos (Edital 2012).E-mail: isabelinhasabino@yahoo.com.br

\section{Recebido em março de 2016.}

Aprovado para publicação em fevereiro de 2017. 
